\title{
Secondary fibrosarcoma of the brain stem treated with cyclophosphamide and Imatinib
}

\author{
Daniela Alexandru • Denise K. Van Horn • \\ Daniela Annenelie Bota
}

Received: 30 July 2009/Accepted: 7 December 2009/Published online: 31 December 2009

(C) The Author(s) 2009. This article is published with open access at Springerlink.com

\begin{abstract}
Radiation-induced midbrain fibrosarcoma is a rare, highly aggressive tumor, which is associated with poor prognosis. We present the case of a 48-year old man with brainstem fibrosarcoma 20 years following radiation therapy received for a pituitary tumor. We discuss this case in the context of the diagnostic criteria for these tumors, and previous reports of secondary and primary sarcomas of the central nervous system.
\end{abstract}

Keywords Fibrosarcoma - Chemotherapy ·

Cyclophosphamide $\cdot$ Imatinib

\section{Introduction}

Secondary fibrosarcoma of the brain is an exceedingly rare tumor, occurring almost exclusively as a complication of therapeutic radiation to a preexisting intracranial tumor [1-5]. Fibrosarcomas are aggressive tumors, with poor prognosis [6-8]. These tumors tend to spread rapidly with extensive involvement of the optic nerves, hypothalamus, and the brain stem, which makes total surgical resection impossible. No clinical trial for brain fibrosarcoma has

D. Alexandru

Department of Neurological Surgery, University of California, Irvine, Irvine, CA, USA

D. K. Van Horn

Department of Pathology, Hoag Hospital, Newport Beach, CA, USA

D. A. Bota $(\square)$

Department of Neurology, University of California, Irvine, Irvine, CA, USA

e-mail: dbota@uci.edu been conducted to date, and current treatment options based on case reports encompass subtotal resection attempts [1], Glia-Site brachytherapy system [9], or chemotherapy [2].

We report a case of a 48 year old man who presented with a brainstem lesion 20 years after he received radiation therapy for a pituitary tumor. Upon further investigation, the new tumor was diagnosed as fibrosarcoma secondary to radiation therapy. A subtotal resection of the tumor was performed followed by chemotherapy. We chose to treat the patient with cyclophosphamide and Gleevec chemotherapy and to follow him with serial imaging, which showed evidence of tumor stability for 6 months.

\section{Case report}

\section{Clinical course}

A 48-year old Caucasian man presented to clinic for evaluation of his options for the treatment of brainstem fibrosarcoma. In 1977, 26 years prior to this presentation, the patient was diagnosed with a large pituitary adenoma based on a head computer tomography. Biopsy was not performed at the time. However, he received conformal fractionated radiotherapy of unknown dose. He also had concurrent hydrocephalus and a ventriculo-peritoneal shunt was placed. The patient was asymptomatic until 2003 when he started to develop eye left eyelid drooping and diplopia. A magnetic resonance study performed in February of 2004 showed a right brainstem lesion. Stereotactic needle brain biopsy was performed but the results were inconclusive. The patient was followed with serial neuroimaging until August of 2006 when the tumor experienced significant growth associated with progressive neurologic 
impairment. At that time a second stereotactic biopsy was performed, which also failed to show the pathology of the tumor. In May of 2007, the patient underwent subtotal resection of his large right pontine enhancing mass. Pathology results revealed that the tissue was most consisted with grade 2 fibrosarcoma. Post operatively the patient suffered a pseudomeningocele at the incision site, which required a VP shunt revision. Subsequently he presented to our clinic for reevaluation of this therapeutic options. After careful consideration of the different options available we decided to use a combination of metronomic cyclophosphamide at $50 \mathrm{mg}$ a day and Imatinib $400 \mathrm{mg}$ a day. The choice of Imatinib was based on the newest published data on the soft-tissue sarcoma and gastrointestinal stromal tumors sensitivity to Imatinib [10] and the recent clinical trials showing that this chemotherapy agent is a potential option for primary malignant gliomas [11]. Cyclophosphamide is very commonly used in the treatment of multiple CNS malignancies such as malignant glioma and meningioma [12], and also shows good activity in the treatment of systemic fibrosarcoma [13] which motivates our decision to include this drug in this patient's regimen.

The patient tolerated the treatment well, with slow improvement in his neurologic function and with minimal (grade II) chemotherapy-related hematologic toxicities. No treatment discontinuation was needed. Serial magnetic resonance studies of the brain showed that the tumor did not grow over the course of 6 month of chemotherapy, measures being stable at $30.2 \mathrm{~mm} \times 35 \mathrm{~mm}$ (November 2007) and $30.4 \mathrm{~mm} \times 35 \mathrm{~mm}$ (May 2008) (Fig. 1c-f). Unfortunately, the patient expired due to bacterial pneumonia with subsequent Gram negative sepsis while continuing to experience neurologic improvement, 6 months after the onset of chemotherapy. At the wish of the family, no autopsy was performed.

\section{Neuropathological examination}

The pathology report indicated that the subtotal resection specimen was most consistent with brainstem tissue (Fig. 2c, d). Microscopical analysis if the specimen revealed spindle cell proliferation, with mild to moderate pleomorphism (Fig. 2a, b). These cells were also negative for EMA, GFAP, Keratin, Melan-A and S 100 (Fig. 2d). In some areas, ten to fifteen percent of these cells reacted with Ki-67 (Fig. 2h). These areas were also positive for Vimentin (Fig. 2f) and showed a delicate reticulin network (Fig. 2e). Faint to moderate positivity for $\mathrm{p} 53$ was demonstrated in some areas. A desmin stain was also positive. Within the brain tissue there were some areas of necrosis in which macrophages could be seen.

\section{Imaging examination}

T1 weighted axial and sagittal images delineated a gadolinium enhancing midbrain mass with lesional edema. T2
Fig. 1 Axial and coronal MRI T1 images with contrast.

a, b May 2007 showing tumor in the midbrain region.

c, d November 2007 showing tumor progression.

e, f May 2008 showing tumor stability following

chemotherapy
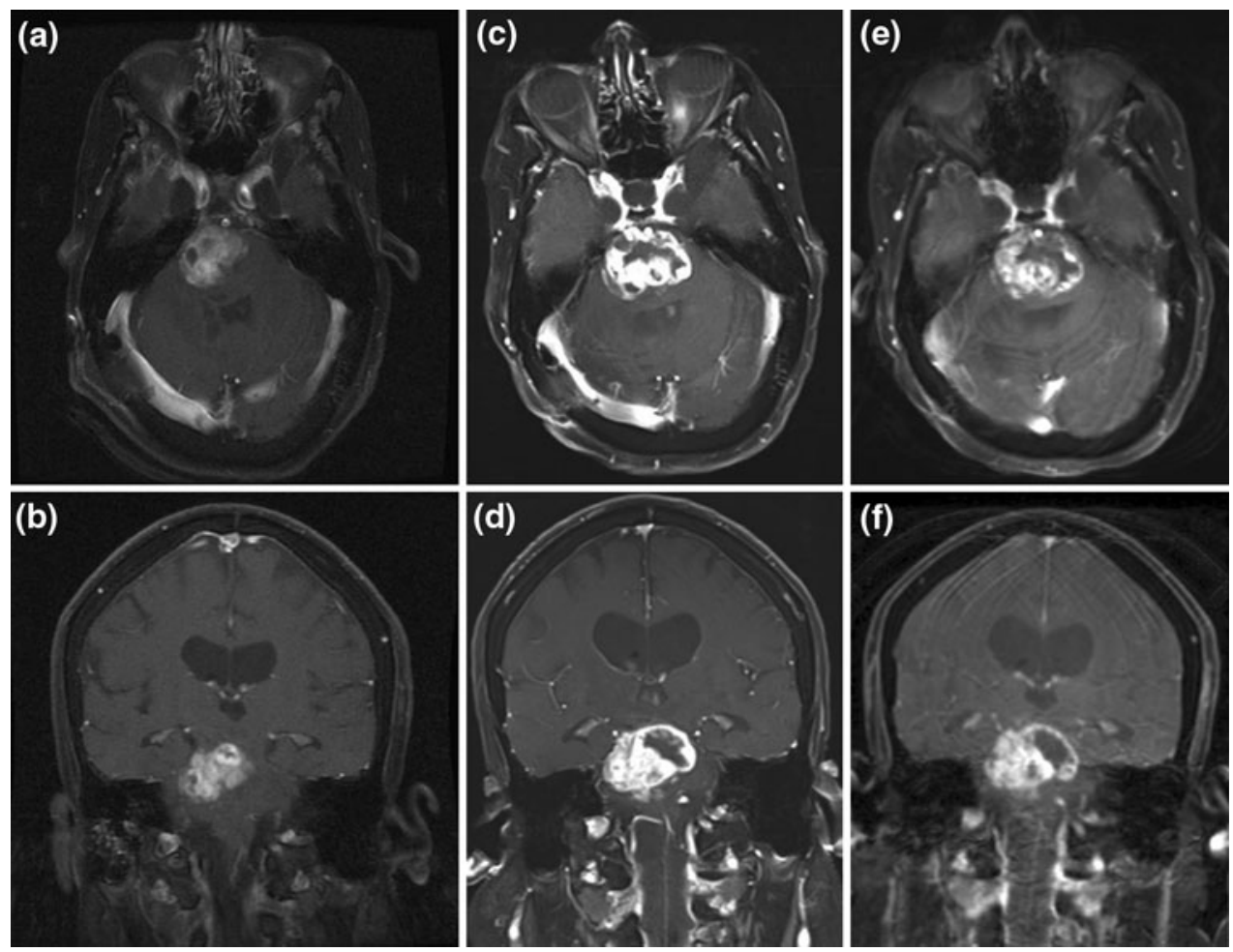
Fig. 2 Pathology slides fibrosarcoma: a Spindled pleomorphic cells of fibrosarcoma, mitosis in upper left corner. b Mitotic figure and spindle pleomorphic cells of fibrosarcoma. c H\&E stains of individual malignant cells infiltrating pons. d S-100 immunohistochemical stain, negative. e Reticulin stain showing delicate reticulin fibers between malignant cells. f Vimentin immunohistochemical stain, strongly positive. g GFAP immunohistochemical stain, negative. h Ki-67 immunohistochemical stain, positive, indicating proliferative activity
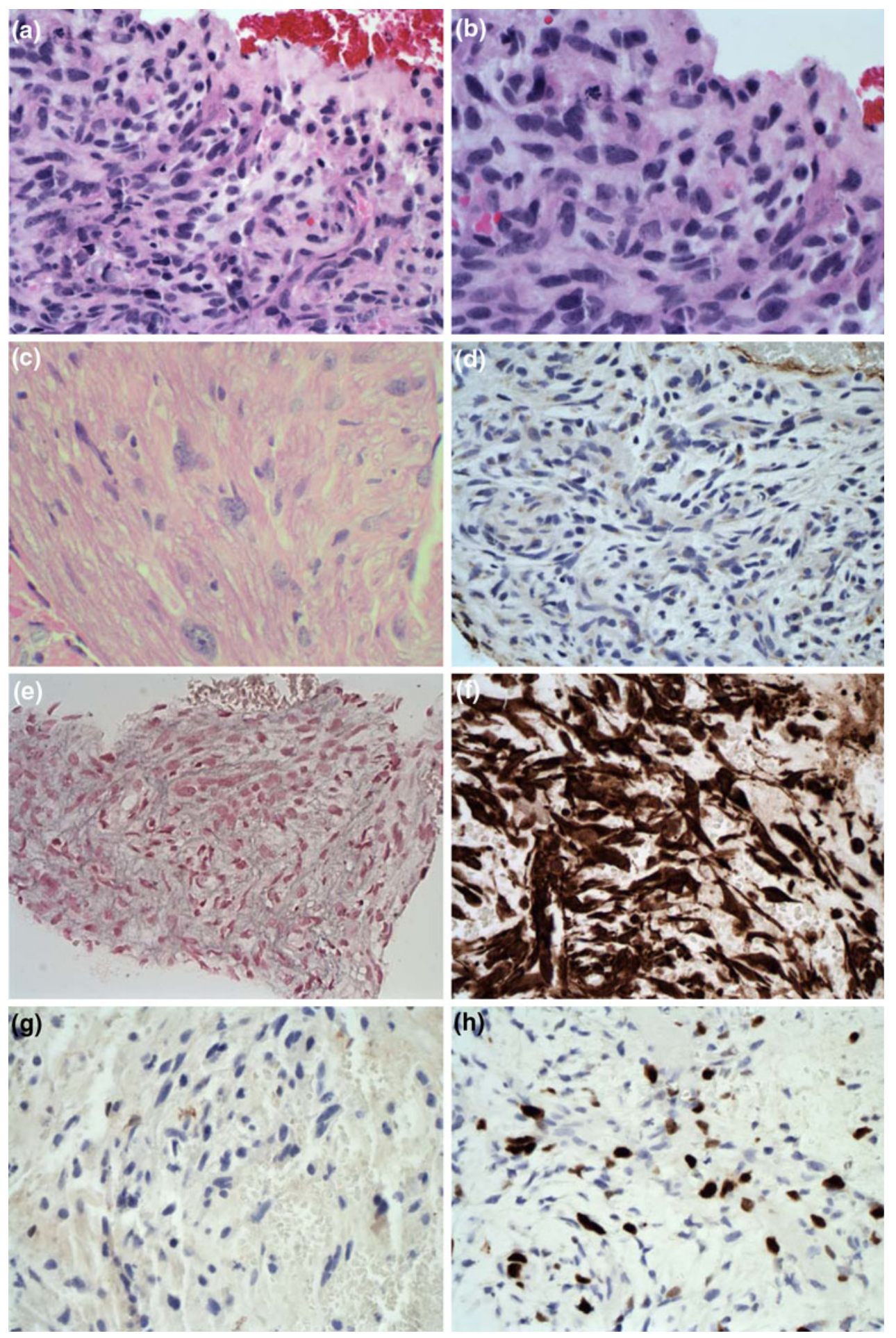

weighted axial images demonstrated a heterogenous hyperintensity corresponding to the gadolinium-enhancing areas (Fig. 1). Compared o the MRI from May 2007 the MRI from November 2007 showed rapidly expanding tumor (Fig. 1). The follow-up MRIs obtained at 6 months showed stability of the tumor over a period of 6 month (Fig. 1).

\section{Discussion}

Sarcomas of the central nervous system are exceedingly rare tumors, accounting for only $1.5 \%$ of the total intracranial tumors $[14,15]$. They can be classified in four categories. First category includes primary brain sarcomas arising from the mesenchymal tissues. Second category 
encompasses sarcomatous transformation of a preexisting brain tumor, such as meningioma or glioma. Third category includes radiation induced sarcomas and fourth category is composed of systemic metastatic sarcomas to the central nervous system [1-4, 6-8, 15-17]. Post irradiation fibrosarcoma of the central nervous system is characterized by quick and extensive local invasion of the tissues [1, 3]. Literature indicates that these tumors are associated with rapid clinical decline $[1,2,8]$.

In our patient, the histopathologic diagnosis of sarcoma was based on the hematoxylin and eosin sections which showed a highly malignant tumor with sheets of spindle shaped cells, and oval-shaped nuclei with atypia and pleomorphism. The positive Vimentin stain also supported the diagnosis of sarcoma, since Vimentin is the major subunit protein in the intermediate filaments of mesenchymal cells. The delicate reticulin pattern surrounding the tumor cells with extensive areas of collagen deposition as well as the positive desmin stain was also consistent with the diagnosis of fibrosarcoma (Fig. 2).

Similar to other literature reports, there was no histogenic relationship of the sarcoma to the pituitary adenoma: immunostaining failed to show evidence of endocrine function in the fibrosarcoma specimen. At the same time, the GFAP stain was negative indicating that the tumor was not a gliosarcoma. This fibrosarcoma most likely appeared from the adjacent mesenchymal tissues in the sella turcica, dura, the optic sheath and the basal meninges which received radiation therapy along with the original pituitary tumor. Literature reports indicate that fibrosarcoma can convert to glioblastoma in the setting of continued radiation received by brain parenchyma [18]. This malignant transformation of the primary mesenchymal tumor may be due to the effect radiation has on the adjacent glial tissues and reactive astrocytes, as well as on the pluripotent mesenchymal cells in the tumor bed to undergo further malignant transformation [18]. This process is certainly possible in our patient, although the GFAP stain indicated that the tumor did not have a glial component. Since no autopsy was performed to analyze the entire tumor mass, it is uncertain if areas of the tumor underwent transformation to gliosarcoma.

Radiation-induced fibrosarcoma has become more common in the recent years as the number of long-term survivors consistently increased with new methods of treatment. We

Table 1 Literature review of post irradiation fibrosarcoma cases

\begin{tabular}{|c|c|c|c|c|c|}
\hline Study & Age & Sex & $\begin{array}{l}\text { Total radiation } \\
\text { to tumor }\end{array}$ & $\begin{array}{l}\text { Latent } \\
\text { period }\end{array}$ & $\begin{array}{l}\text { Duration of tumor } \\
\text { after radiation (months) }\end{array}$ \\
\hline Terry et al. [23] Case 1 & 47 & $\mathrm{~F}$ & 7,500 & 6.5 & 3 \\
\hline Terry et al. [23] Case 2 & 44 & $\mathrm{M}$ & 6,400 & 2.5 & 8.5 \\
\hline Terry et al. [23] Case 3 & 26 & $\mathrm{~F}$ & 6,500 & 12 & 2 \\
\hline Newton et al. [24] & 28 & $\mathrm{~F}$ & 3,910 & 10 & 6 \\
\hline Goldberg et al. [25] Case 1 & 28 & $\mathrm{~F}$ & 3,940 & 10.5 & 1 \\
\hline Goldberg et al. [25] Case 2 & 31 & $\mathrm{~F}$ & 6,000 & 20 & 1 \\
\hline Greenhouse [26] & 24 & $\mathrm{~F}$ & 8,000 & 7.3 & $11 / 3$ \\
\hline Waltz and Brownell [27] Case 1 & 38 & M & 3,500 & 8 & 1 \\
\hline Waltz and Brownell [27] Case 2 & 42 & M & 4,000 & 5 & 6 \\
\hline Ahmad and Fayos [28] & 46 & M & 4,092 & 10 & Unknown \\
\hline Powell et al. [29] & 52 & M & 5,000 & 13 & 6 \\
\hline Pieterse et al. [30] & 48 & M & 4,500 & 18 & 12 \\
\hline Shi et al. [1] & 54 & M & 5,000 & 8 & 5 \\
\hline Chang and Pool [31] & Unknown & Unknown & Unknown & 27 & Unknown \\
\hline Wright [32] & Unknown & Unknown & Unknown & 15 & Unknown \\
\hline Amine and Sugar [33] & 16 & Unknown & 5,100 & 10 & Unknown \\
\hline Gerlach and Janisch [34] & 26 & Unknown & 6,000 & 20 & Unknown \\
\hline Coppeto and Roberts [35] & 46 & Unknown & 10,000 & 7 & Unknown \\
\hline Shin et al. [36] & 33 & Unknown & 5,000 & 11 & Unknown \\
\hline Vikhert and Kasumova [37] Case 1 & 43 & Unknown & 10,100 & 12 & Unknown \\
\hline Vikhert and Kasumova [37] Case 2 & 58 & Unknown & 12,000 & 13 & Unknown \\
\hline Vikhert and Kasumova [37] Case 3 & 50 & Unknown & Unknown & 8 & Unknown \\
\hline Pages and Broquerie [38] & 23 & Unknown & 5,400 & 27 & Unknown \\
\hline Nagatani et al. [39] & 55 & Unknown & 5,000 & 2 & Unknown \\
\hline Martin et al. [40] & 18 & Unknown & 4,500 & 5 & Unknown \\
\hline
\end{tabular}


Table 2 Literature cases regarding chemotherapy treatment of fibrosarcoma

\begin{tabular}{lll}
\hline & Fibrosarcoma therapy & Overall survival \\
\hline Patient $11[4]$ & High dose chemotherapy (unspecified) and stem cell rescue & 7 years \\
Patient 22 [2] & Procarbazine, lomustine, vincristine & 10 months \\
Patient $3[22]$ & Diaziquone & Unknown \\
Patient $4[22]$ & Semustine and doxorubicin & Unknown \\
\hline
\end{tabular}

have identified 25 cases in the literature (Table 1), where patients received radiation therapy for a pituitary adenoma. Subsequently these patients developed fibrosarcomas with a latent period of 2.5-20 years, with most of the patients developing the secondary tumor approximately 10-12 years after receiving radiation therapy for the initial tumor. From analyzing these cases, we also inferred a clinical picture of fibrosarcoma as a highly aggressive tumor, with extensive infiltration in the surrounding tissue and quick progression.

The surgical treatment for these tumors is highly limited-the areas the tumor extends into are not easily accessible by traditional or modern neurosurgical techniques, and the resection is limited due to the highly eloquent areas the tumor invades. Chemotherapy or additional radiation are the best options for treating these highly malignant tumors affecting the brain [19-21].

Presently no clinical trials have been conducted to define the optimal chemotherapy regimen appropriate to treat these tumors. We were able to identify in our extensive literature search only four case reports which have used chemotherapy for the treatment of secondary fibrosarcomas of the brain (see Table 2). The overall survival of the adult patients described in the case reports were similar to the one described by us [22]. However, none of the older chemotherapy regimens contained pathway-selective drugs. The drugs used had the potential for severe sideeffects and impact on the patient quality of life [2, 9, 14].

With recent advances in molecularly targeted treatments for cancers, new agents are emerging to treat different types of sarcomas. Imatinib is one molecule which is gaining acceptance in the treatment of other types of fibrosarcoma, such as dermatofibrosarcoma and soft-tissue sarcomas. Cyclophosphamide is another agent that is valuable in the treatment of brain neoplasms and has been used to treat sarcomas with some success. As the two chemotherapy agents have different targets in the neoplastic cells, their combination has a potential synergistic activity. In our case, this regimen was also very well tolerated, with no limiting toxicities.

\section{Conclusions}

Post radiation fibrosarcomas most likely arise from the adjacent tissues which have been exposed to radiation in the process of treating the primary tumor. The treatment of these tumors is not well defined, and this severely impacts their prognosis. New research on the molecular pathology of radiation-induced brain fibrosarcoma and more targeted therapies is currently needed. Aggressive therapeutic approaches are required to maintain tumor control. We found metronomic cyclophosphamide and Imatinib to be appropriate therapeutic options for maintaining local tumor control in a patient with a very aggressive tumor. Our treatment regimen provided progression free survival for 6 months.

Open Access This article is distributed under the terms of the Creative Commons Attribution Noncommercial License which permits any noncommercial use, distribution, and reproduction in any medium, provided the original author(s) and source are credited.

\section{References}

1. Shi T, Farrell MA, Kaufmann JC (1984) Fibrosarcoma complicating irradiated pituitary adenoma. Surg Neurol 22(3):277-284

2. Mizuno M, Yoshida J, Shimosawa S, Kuchiwaki H (1989) [Intracranial fibrosarcoma fifteen years after radiotherapy in bilateral retinoblastomas: effect of combined chemotherapy with cisplatin and VP-16]. No Shinkei Geka 17(7):653-657

3. Prabhu SS, Aldape KD, Gagel RF, Benjamin RS, Trent JC, McCutcheon IE (2003) Sarcomatous change after sellar irradiation in a growth hormone-secreting pituitary adenoma. Can $\mathbf{J}$ Neurol Sci 30(4):378-383

4. Erguvan-Onal R, Onal C, Gurlek A, Alkan A, Erkal HS, Mizrak B (2004) Metastatic fibrosarcoma of the brain: transformation from conventional to epithelioid form-case report. Neurol Med Chir (Tokyo) 44(9):497-501

5. Rovirosa A, Vicente P, Bellmut J et al (1992) Meningeal fibrosarcoma: a case report and review of the literature. Acta Neurol Belg 92(1):30-35

6. Torres G, Petit F, Vilchez V et al (2007) Primary cerebral fibrosarcoma in a child. Clin Neuropathol 26(6):284-287

7. Donnet A, Figarella-Branger D, Grisoli F (1999) Primary meningeal fibrosarcoma: a particular neuroradiological presentation. J Neurooncol 42(1):79-83

8. Cai N, Kahn LB (2004) A report of primary brain fibrosarcoma with literature review. J Neurooncol 68(2):161-167

9. Fraser RW, Limentani SA, Dollar JD, Asher A (2003) Recurrent primary fibrosarcoma of the brain treated with the GliaSite brachytherapy system: case report. Surg Neurol 60(6):579-583 discussion 583-574

10. van Oosterom AT, Judson IR, Verweij J et al (2002) Update of phase I study of Imatinib (STI571) in advanced soft tissue sarcomas and gastrointestinal stromal tumors: a report of the 
EORTC Soft Tissue and Bone Sarcoma Group. Eur J Cancer 38(Suppl 5):S83-S87

11. Reardon DA, Egorin MJ, Quinn JA et al (2005) Phase II study of Imatinib mesylate plus hydroxyurea in adults with recurrent glioblastoma multiforme. J Clin Oncol 23(36):9359-9368

12. Kesari S, Schiff D, Doherty L et al (2007) Phase II study of metronomic chemotherapy for recurrent malignant gliomas in adults. Neuro Oncol 9(3):354-363

13. Kynaston JA, Malcolm AJ, Craft AW et al (1993) Chemotherapy in the management of infantile fibrosarcoma. Med Pediatr Oncol 21(7):488-493

14. Kaminski JM, Yang CC, Yagmai F, Movsas B, Lee M, Barrett JT (2000) Intracranial fibrosarcoma arising 5 years after chemotherapy alone for glioblastoma multiforme in a child. Pediatr Neurosurg 33(5):257-260

15. Russell DRL (1989) Pathology of tumors of the nervous system, 5th edn. Williams \& Wilkins, Baltimore

16. Burger PC, Scheithauer B, Vogel FS (2002) Surgical pathology of the nervous system and its coverings in brain tumors, 4th edn. Churchill Livingstone, Philadelphia, pp 193-437

17. McDonald P, Guha A, Provias J (1997) Primary intracranial fibrosarcoma with intratumoral hemorrhage: neuropathological diagnosis with review of the literature. J Neurooncol 35(2): 133-139

18. Adeleye AO, Fellig Y, Umansky F, Shoshan Y (2009) Rapid growth of primary cerebral fibrosarcoma with conversion to glioblastoma at second recurrence. J Neurooncol 92(2):233-238

19. Loh ML, Ahn P, Perez-Atayde AR, Gebhardt MC, Shamberger RC, Grier HE (2002) Treatment of infantile fibrosarcoma with chemotherapy and surgery: results from the Dana-Farber Cancer Institute and Children's Hospital, Boston. J Pediatr Hematol Oncol 24(9):722-726

20. Izawa M, Chernov M, Hayashi M, Kubota Y, Kasuya H, Hori T (2006) Fatal intratumoral hemorrhage immediately after gamma knife radiosurgery for brain metastases: case report. Minim Invasive Neurosurg 49(4):251-254

21. Pirnik Z, Bundzikova J, Bizik J, Hulin I, Kiss A, Mravec B (2008) Activity of brain stem groups of catecholaminergic cells in tumor-bearing rats: response to immobilization stress. Ann N Y Acad Sci 1148:141-147

22. Gaspar LE, Mackenzie IR, Gilbert JJ et al (1993) Primary cerebral fibrosarcomas. Clinicopathologic study and review of the literature. Cancer 72(11):3277-3281

23. Terry RD, Hyams VJ, Davidoff LM (1959) Combined nonmetastasizing fibrosarcoma and chromophobe tumor of the pituitary. Cancer 12(4):791-798
24. Newton TH, Burhenne HJ, Palubinskas AJ (1962) Primary carcinoma of the pituitary. Am J Roentgenol Radium Ther Nucl Med $87: 110-120$

25. Goldberg MB, Sheline GE, Malamud N (1963) Malignant intracranial neoplasms, following radiation therapy for acromegaly. Radiology 80:465-470

26. Greenhouse AH (1964) Pituitary sarcoma; a possible consequence of radiation. JAMA 190:269-273

27. Waltz TA, Brownell B (1966) Sarcoma: a possible late result of effective radiation therapy for pituitary adenoma. Report of two cases. J Neurosurg 24(5):901-907

28. Ahmad K, Fayos JV (1978) Pituitary fibrosarcoma secondary to radiation therapy. Cancer 42(1): 107-110

29. Powell HC, Marshall LF, Ignelzi RJ (1977) Post-irradiation pituitary sarcoma. Acta Neuropathol 39(2):165-167

30. Pieterse S, Dinning TA, Blumbergs PC (1982) Postirradiation sarcomatous transformation of a pituitary adenoma: a combined pituitary tumor. Case report. J Neurosurg 56(2):283-286

31. Chang CH, Pool JL (1967) The radiotherapy of pituitary chromophobe adenomas: an evaluation of indication, technic, and result. Radiology 89(6):1005-1016

32. Wright R (1950) Fibrosarcoma. J Kans Med Soc 51(11):515-516

33. Amine AR, Sugar O (1976) Suprasellar osteogenic sarcoma following radiation for pituitary adenoma. Case report. J Neurosurg 44(1):88-91

34. Gerlach H, Janisch W (1979) [Intracranial sarcoma after radiotherapy of a pituitary adenoma]. Zentralbl Neurochir 40(2): 131-136

35. Coppeto JR, Roberts M (1979) Fibrosarcoma after proton-beam pituitary ablation. Arch Neurol 36(6):380-381

36. Shin $\mathrm{H}$, Namba H, Ishige $\mathrm{N}$ et al (1980) [Pituitary fibrosarcoma secondary to radiation therapy for the treatment of chromophobe adenoma (author's transl)]. No Shinkei Geka 8(7):605-614

37. Vikhert TM, Kasumova S (1980) [Radiation fibrosarcoma of the pituitary]. Zh Vopr Neirokhir Im N N Burdenko 4:57-58

38. Pages A, Broquerie E (1979) [Eighteen cases of desmomas (author's transl)]. Sem Hop 55(21-22):1109-1113

39. Nagatani M, Ikeda T, Otsuki H et al (1984) [Sellar fibrosarcoma following radiotherapy for prolactinoma]. No Shinkei Geka $12(3$ Suppl):339-346

40. Martin WH, Cail WS, Morris JL, Constable WC (1980) Fibrosarcoma after high energy radiation therapy for pituitary adenoma. AJR Am J Roentgenol 135(5):1087-1090 